\title{
Trends in fruit, vegetable and salad intakes in 9-10-year-old schoolchildren living in Liverpool, 2000-2005
}

\author{
B Johnson ${ }^{1, *}$ and AF Hackett ${ }^{2}$ \\ 'Department of Community Dietetics, Abercromby Health Centre, Grove Street, Liverpool L7 7HG, \\ UK: ${ }^{2}$ Liverpool John Moores University, IM Marsh Campus, Barkhill Road, Liverpool L17 6BD, UK
}

Submitted 26 January 2006: Accepted 17 May 2006

\begin{abstract}
Objective: To report on the fruit, vegetable and salad intakes of Liverpool schoolchildren aged 9-10 years over a 5-year period (2000-2005).

Design: Cross-sectional observational study.

Setting: Between 75 and 100 Liverpool primary schools took part in each survey year. Subjects: Subjects consisted of five separate cohorts of 9-10-year-old children from all areas of the city.

Main outcome measures: Number and proportion of boys and girls who reported eating fruit, vegetables and salad on the previous day.

Results: There was an upward trend in the reported intake of fruit between 2002 and 2005. Girls were more likely than boys to report eating fruit $(P<0.001)$. The trend in salad intake was positive. Between 2000 and 2005 there were significant increases in the number of boys $\left(\chi^{2}=17.57, P=0.001\right)$ and girls $\left(\chi^{2}=80.56, P=0.001\right)$ eating salad. Girls were significantly more likely to eat salad than boys in all years $\left(\chi^{2}=58.75, P=0.001\right)$. Trends in vegetable intake were similar to those for salad, with both sexes reporting yearly increases over the 5 -year period. The increase in the number of boys who reported eating vegetables between 2000 and 2005 was 23.5\% $\left(\chi^{2}=32.9, P=0.000\right)$. In girls there was a $44.8 \%$ increase over the same period $\left(\chi^{2}=110.3, P<0.000\right)$.

Conclusions: The data reveal positive trends in the fruit, vegetable and salad intakes of Liverpool schoolchildren between 2000 and 2005. Further research is needed to elucidate the specific factors that have enabled the changes to take place.
\end{abstract}

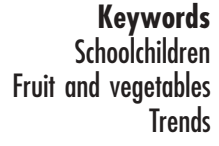

Food-related ill-health is estimated to cost the UK National Health Service £6 billion each year. Raynor and Scarborough $^{1}$ also suggest that $10 \%$ of disability-adjusted life years can be attributed to food-related factors. A diet rich in vegetables and fruit is thought to be one dietary factor beneficial to health, and may be important in reducing levels of heart disease ${ }^{2}$, stroke ${ }^{3}$ and cancers in adulthood $^{4}$. The World Health Organization (WHO) ${ }^{2}$ recommends an intake of fruit and vegetables of at least $400 \mathrm{~g} \mathrm{day}^{-1}$ (excluding tubers); this was translated into advice for the population to eat five or more portions of fruit and vegetables per day. Evidence from a national survey on the eating habits of schoolchildren showed them to be eating only half the recommended daily five portions ${ }^{5}$. More recently, a survey investigating the fruit and vegetable intake of children in nine European countries $^{6}$ reported mean consumption of fruit and vegetables ranging from 143 to $265 \mathrm{~g} \mathrm{day}^{-1}$ (1.7 to 3.3 portions, respectively). The same report showed that only $17.9 \%$ of girls and $17.3 \%$ of boys had intakes at or above the WHO recommendation of $400 \mathrm{~g} \mathrm{day}^{-1}$.

The Sportslinx Programme ${ }^{7}$ has collected data annually on the eating habits and activity patterns of Liverpool primary-school children (Year 5) since 1998. Children complete questionnaires on diet and physical activity patterns and preferences. In addition, anthropometric measurements, including height, weight, body mass index and triceps and biceps skinfold measures, are also collected. The data provide a cross-sectional 'picture' of two important lifestyle factors in Year 5 primary-school children: physical activity and food intake. The data can be used to monitor trends and inform local planning of diet and physical activity interventions to promote healthy lifestyles in schools and local communities.

There have been few systematic city-wide surveys of the eating habits of schoolchildren in the UK, and very little data indicating recent trends. The Schools Health Education Unit (SHEU) has collected data from young people in primary and secondary schools on a range of health-related issues, including food choices, to measure trends in intake over the last decade ${ }^{8}$. The period between has seen greatly increased attention given to fruit and vegetable intake in children, including the 5-a-day campaign and the National School Fruit initiative, and it might be anticipated that rises in consumption would occur as a result. This paper presents data on the reported 
intakes of fruit, vegetables and salad collected from boys and girls attending primary schools in Liverpool during the last five years.

\section{Material and methods}

\section{Sample}

An opportunistic sample of schools took part in each survey year. All primary schools in Liverpool were contacted in writing and invited to take part in the Sportslinx Programme during each survey year. All children in Year 5 (9-10 years old) were eligible to take part.

\section{Measures}

Five surveys were conducted as part of the Sportslinx Programme between 2000 and 2005. Children in primary school Year 5 completed a well-established and validated Food Intake Questionnaire (FIQ) ${ }^{9}$ during each survey year. Parents of all those who took part provided written consent for their child to take part in the Sportslinx survey.

The FIQ $^{9}$ is an epidemiological tool for assessing the eating habits of children. It is an adapted recall method which collects food-based data on the consumption of specific foods eaten on the previous day. Using a foodbased approach to measure intake is consistent with the way messages on healthy eating are delivered, and the items included have been shown to be representative of the general advice given by dietitians in terms of foods to eat more or less of to achieve a healthy diet ${ }^{10}$.

The FIQ provides information on food intake at the group level, and was not designed to estimate nutrient intake. It has been used for over 15 years to monitor the eating habits of schoolchildren nationally ${ }^{11}$ and locally in Liverpool $^{12}$. The FIQ asks children a basic stem question: 'Did you at any time yesterday eat any amount of...' The question is then followed by a list of food-related items. The main outcome variables are the number and proportion of children answering yes and no to specific FIQ items. For the purpose of this analysis only data relating to the reported consumption of fruit, salad and vegetables are presented.

\section{Statistical analysis}

The data were analysed using SPSS 13.01 (SPSS Inc., 2004). The chi-square test was used to assess differences in the proportions of boys and girls eating fruit, vegetables and salad and to compare differences between survey years.

\section{Results}

Table 1 describes the gender profile and the number of schools that took part for each survey year. FIQs were completed by 8490 boys and 8138 girls between 2001 and 2005 and were included in the analysis. The number of schools that were eligible to take part between 2001 and
Table 1 Number of schools and gender profile of the children who took part in each survey

\begin{tabular}{lcccccc}
\hline & \multirow{2}{*}{$\begin{array}{c}\text { Number of schools } \\
\text { taking part }\end{array}$} & \multicolumn{2}{c}{ Boys } & & \multicolumn{2}{c}{ Girls } \\
\cline { 3 - 4 } & 79 & $n$ & $\%$ & & $n$ & $\%$ \\
\hline $2000-2001$ & 70 & 1989 & 51 & & 1901 & 49 \\
$2001-2002$ & 77 & 1622 & 54 & & 1385 & 46 \\
$2002-2003$ & 100 & 1459 & 51 & & 1420 & 49 \\
$2003-2004$ & 75 & 1816 & 50 & & 1843 & 50 \\
$2004-2005$ & & 1604 & 50 & & 1589 & 50 \\
\hline
\end{tabular}

2005 varied each year. Over the 5-year period 64-95\% of eligible schools took part in the surveys.

\section{Fruit intake, 2000-2005}

The proportions of boys and girls who reported eating fruit on the previous day are presented in Table 2 . There was a marked significant increase in the number of girls who reported eating fruit during the 5-year period: 1108 (70.7\%) of girls in 2000-2001, increasing to 1257 (80.8\%) in 2004-2005. The trend for boys was similar except for survey year 2002-2003, where a small decrease $(0.5 \%$ points) was seen compared with the previous year $(70.9 \%$ in 2002-2003 vs. $71.4 \%$ in 2001-2002). In general, girls were more likely to report eating fruit than boys $\left(\chi^{2}=9.33, \mathrm{df}=1, P=0.002\right)$. There were also statistically significant differences between boys and girls each year between 2002 and 2005. The one exception over the 5 -year period was 2000-2001, when more boys (71.5\%) reported eating fruit than girls (70.7\%).

\section{Salad intake, 2000-2005}

There was a clear upward trend in the reported intake of salad vegetables over the 5 -year period in both boys and girls (Table 3). More girls reported that they had eaten salad on the previous day than boys, in all years, and the differences were statistically significant $\left(\chi^{2}=58.75\right.$, $\mathrm{df}=1, P=0.001)$. Over the 5 -year period there was a $25 \%$ increase in the number of boys eating salad, the figures ranged from $24.8 \%$ in $2000-2001$ to $31.0 \%$ in $2004-$ $2005\left(\chi^{2}=17.57, \mathrm{df}=4, P=0.001\right)$. In girls the trend was more dramatic. Four hundred and twenty-eight (27.7\%) girls reported eating salad in 2000-2001; this increased to

Table 2 Proportions of boys and girls who reported eating fruit on the previous day by school year

\begin{tabular}{lrrrrrr}
\hline & \multicolumn{2}{c}{ Boys } & & \multicolumn{2}{c}{ Girls } & \\
\cline { 2 - 3 } Year & \multicolumn{1}{c}{$n$} & & \multicolumn{1}{c}{$n$} & $\%$ & $P_{\text {-value }}$ \\
\hline $2000-2001$ & 1137 & 71.5 & & 1108 & 70.7 & 0.33 \\
$2001-2002$ & 964 & 71.4 & 873 & 71.9 & 0.41 \\
$2002-2003$ & 975 & 70.9 & & 1021 & 75.0 & 0.01 \\
$2003-2004$ & 1334 & 75.0 & & 1409 & 77.7 & 0.03 \\
$2004-2005$ & 1209 & 76.8 & & 1257 & 80.8 & $<0.01$ \\
\hline
\end{tabular}

* Significance level for chi-square test comparing boys and girls. 
Table 3 Proportions of boys and girls who reported eating salad on the previous day by school year

\begin{tabular}{lcccccr}
\hline & \multicolumn{2}{c}{ Boys } & & \multicolumn{2}{c}{ Girls } & \\
\cline { 2 - 3 } Year & $n$ & $\%$ & & $n$ & $\%$ & \\
\hline $2000-2001$ & 383 & 24.8 & & 428 & 27.7 & $<0.01$ \\
$2001-2002$ & 344 & 26.2 & & 339 & 28.5 & 0.10 \\
$2002-2003$ & 370 & 27.0 & & 440 & 32.7 & $<0.01$ \\
$2003-2004$ & 489 & 28.2 & & 615 & 34.8 & $<0.00$ \\
$2004-2005$ & 485 & 31.0 & 638 & 41.4 & $<0.00$ \\
\hline
\end{tabular}

*Significance level for chi-square test comparing boys and girls.

$638(41.4 \%)$ in $2004-2005$, representing a $49.5 \%$ increase over the 5-year period ( $\chi^{2}=80.56$, df $\left.=4, P=0.001\right)$.

\section{Vegetable intake, 2000-2005}

During the period between 2000 and 2003 the numbers and proportions of boys and girls eating vegetables on the previous day were similar (Table 4). In 2003-2004 and 2004-2005 there was an increase in the numbers of boys and girls who reported eating vegetables compared with 2000-2003, with clear and significant gender differences. During 2003-2004, 676 boys (38.6\%) boys and 775 (43.6\%) girls reported eating vegetables $\left(\chi^{2}=8.38, \mathrm{df}=1\right.$, $P=0.04$ ). There was a similar upward trend for $2004-$ 2005 , with $37.5 \%$ of boys and $44.3 \%$ of girls reporting vegetable consumption $\left(\chi^{2}=13.45\right.$, $\mathrm{df}=1, P<0.00$ ).

Overall there was a $23.5 \%$ increase in reported vegetable consumption between 2001 and 2005 in boys $\left(\chi^{2}=32.9, \mathrm{df}=4, P<0.00\right)$. In girls the increase for the same period was $44.8 \%\left(\chi^{2}=110.3 \mathrm{df}=4, P<0.00\right)$.

\section{Discussion}

Information describing trends in fruit and vegetable consumption in schoolchildren in the UK over the last five years is extremely limited and the results presented in this paper are both encouraging and timely, particularly as public health policy over the last three years has focused strategies and interventions on the promotion of fruit and vegetable consumption as a healthy option for schoolchildren.

There were significant, positive trends in the reported intakes of fruit, vegetables and salad over a 5-year period, in both sexes. Despite the low proportions of boys and girls

Table 4 Proportions of boys and girls who reported eating vegetables on the previous day by year

\begin{tabular}{lccccrr}
\hline & \multicolumn{2}{c}{ Boys } & & \multicolumn{2}{c}{ Girls } & \\
\cline { 2 - 3 } Year & $n$ & $\%$ & & $n$ & $\%$ & $P$-value* \\
\hline $2000-2001$ & 479 & 30.7 & & 469 & 30.6 & 0.49 \\
$2001-2002$ & 424 & 32.1 & & 373 & 31.4 & 0.36 \\
$2002-2003$ & 477 & 35.0 & & 471 & 35.2 & 0.48 \\
$2003-2004$ & 676 & 38.6 & & 775 & 43.6 & 0.04 \\
$2004-2005$ & 591 & 37.9 & & 685 & 44.3 & $<0.00$ \\
\hline
\end{tabular}

* Significance level for chi-square test comparing boys and girls. who reported eating vegetables and salad, the year-on-year increases between 2000 and 2005 are very encouraging. Fruit intake in boys and girls also showed an upward trend over the last three years. Compared with other surveys using the FIQ ${ }^{11,12}$, the proportion of girls who reported eating fruit during the period 2004-2005 are the highest recorded. There have been differing trends in fruit intake described by other studies. The $\mathrm{SHEU}^{8}$ reported on the fruit intakes of schoolchildren across the UK over a 10-year period between 1990 and 2000. Their results showed a general decline in fruit intake from 1990 to 1998, followed by a small increase between 1999 and 2000, and then a further decline in the period 2000-2001. Crucially, the present study shows a steady rise since 2000. Inchley et al. ${ }^{13}$ in contrast reported an increase in fruit and vegetable consumption in Scottish schoolchildren, particularly in girls, between 1990 and 1998. Both studies reported that girls consistently ate more fruit than boys, which was confirmed by the results presented in this paper.

Wells and Nelson ${ }^{14}$ reported that the National School Fruit scheme had a positive influence on both fruit and vegetable intakes in the short term, but failed to influence intake in the long term (in the transition between infant and junior school). The data in the present study are not longitudinal and so whether higher fruit and vegetable intakes are sustained as children grow older is not known. The results described here suggest a consistent trend in intake over a 3-year period for fruit and over a 5-year period for salad and vegetables. It is difficult to assess the specific factors responsible for the positive trends reported in Liverpool; however, promotion of the 5-a-day message, the National School Fruit scheme and local initiatives cannot be overlooked as possible enabling factors. One conclusion from a recent review investigating the determinants of fruit and vegetable consumption ${ }^{15}$ suggested that interventions should aim to improve the availability of fruit and vegetables and improve children's taste preferences.

In Liverpool there have been two school- and community-based programmes promoting the 5-a-day message and the balance of good health. The Sportslinx Programme, based in schools and delivered by Liverpool City Council, and the Community Food Workers Programme $^{16}$, developed by community dietitians, have allowed children to taste new fruits, raised awareness of the benefits of eating more fruit and vegetables, and conducted nutrition clubs in schools and community settings to develop basic cooking skills.

There are limitations to the results presented. It is difficult to compare trends shown in other studies to these data because of the differing methodological approaches used. The data are cross-sectional and represent a separate cohort each year. Also, the FIQ relies on self-reported food intake data and is therefore subject to the usual bias associated with other retrospective dietary methods. As the FIQ relies on a subject's ability to recall his/her food intake on the previous day accurately, it is also susceptible to 
a subject overreporting his/her intake of 'healthy' foods and underreporting his/her intake of 'less healthy' foods. The data were also collected on school days and may fail to account for some foods and snacks consumed at the weekend. Nevertheless, the results represent a positive trend: at the least that more children feel they should report eating more fruit and vegetables.

Overall, this paper has described positive trends in fruit, salad and vegetable consumption over a 5-year period. Further research is needed to elucidate the specific factors that have enabled the reported changes to take place. Regardless of causality however, it demonstrates that improvement can be achieved.

\section{Acknowledgements}

Sources offunding: Sportslinx is funded by the Neighbourhood Renewal Fund.

Conflict of interest declaration: No conflict of interest declared.

Authorship responsibilities: Both authors have participated fully in the research process.

\section{References}

1 Raynor M, Scarborough P. The burden of food related ill health in the UK. Journal of Epidemiology and Community Health 2005; 59: 1054-7.

2 World Health Organization (WHO). Diet, Nutrition and the Prevention of Chronic Diseases. WHO Technical Report Series No. 916. Geneva: WHO, 1990.

3 Ness AR, Powles JW. Vegetable and fruit and cardiovascular diseases: a review. International Journal of Epidemiology 1997; 26: 1-13.

4 Maynard M, Gunnell D, Emmett P, Frankel S, Davey Smith G. Fruit, vegetables, and antioxidants in childhood and risk of adult cancer: the Boyd Orr cohort. Journal of Epidemiology and Community Health 2003; 57: 218-25.
5 Gregory J, Lowe S. National Diet and Nutrition Survey: Young People aged 4-18 years. London: Stationery Office, 2000.

6 Yngve A, Wolf A, Poortvliet E, Elmadfa I, Brug J, Ehrenblad B, et al. Fruit and vegetable intake in a sample of 11-year old children in 9 European countries: The Pro Children CrossSectional Survey. Annals of Nutrition \& Metabolism 2005; 49: 236-45.

7 Liverpool City Council. Liverpool Sportslinx Project 20012003. Report on the Health \& Fitness of Liverpool Primary and Secondary School Children. Liverpool: Liverpool City Council, 2004.

8 Schools Health Education Unit (SHEU). Trends: Young People's Food Choices. Attitudes to Healthy Eating and Weight Control 1983-2001. Exeter: SHEU, Exeter University, 2003.

9 Johnson B, Hackett AF, Rouncefield M, Coupopholus AM. Reliability and validity of a food intake questionnaire. Journal of Human Nutrition and Dietetics 2001; 6: 457-66.

10 Johnson B, Hackett AF, Bibby A, Cross J. An investigation of the face validity of a food intake questionnaire: lessons for dietary advice? Journal of Human Nutrition and Dietetics 1999; 12: 307-16.

11 Hackett AF, Kirby SP, Howie M. A national survey of the diet of children aged 13-14 years living in urban areas of the United Kingdom. Journal of Human Nutrition and Dietetics 1997; 10: 323-32.

12 Hackett AF, Gibbon M, Stratton G, Hamil E. Dietary intake of 9-10-year-old and 11-12-year-old children in Liverpool. Public Health Nutrition 2002; 5: 449-55.

13 Inchley J, Todd J, Brice C, Currie C. Dietary trends among Scottish schoolchildren in the 1990's. Journal of Human Nutrition and Dietetics 2001; 14: 207-16.

14 Wells L, Nelson M. The National School Fruit Scheme produces short-term but not longer-term increases in fruit consumption in primary school children. British Journal of Nutrition 2005; 93: 537-43.

15 Blanchette L, Brug J. Determinants of fruit and vegetable consumption among 6-12-year-old children, and effective interventions to increase consumption. Journal of Human Nutrition and Dietetics 2005; 18: 431-43.

16 Johnson B, Jones M. It's a lot more than teaching people to cook. Paper presented at Gth Annual Public Health Forum: Working Together for the Public's Health, University of Lancaster, Lancaster, UK, 1998. 